\title{
Space-time-frequency analysis of rainfall, runoff and temperature in the Casamance River basin, southern Senegal, West Africa
}

\author{
El-Hadji Ibrahima Thiam ${ }^{1}$ and VP Singh ${ }^{2 \star}$ \\ ${ }^{1}$ Southern Zone Water Management Project, PO Box 582, Kaolack, Senegal, West Africa \\ ${ }^{2}$ Department of Civil and Environmental Engineering, Louisiana State University, Baton Rouge, LA 70783-6405, USA
}

\begin{abstract}
Using long-term data on rainfall and annual runoff, an investigation was made of the spatial and temporal variability of rainfall and runoff in the Casamance River basin located in southern Senegal, West Africa. A 5-year moving average was employed to identify trends in the data. Monthly and annual rainfall tends to have been decreasing, and the annual maximum temperature rising from around the mid-1960s. In addition, there has been a decreasing rainfall gradient from the coast to the interior. The analysis also showed a simultaneous runoff decline as a result of the rainfall decline. Available data on rainfall, temperature, and surface runoff from two upstream stations were used to develop a procedure for estimating runoff from the annual surplus values of precipitation minus reference evaporation. The resulting equations accounted for $74 \%$ to $77 \%$ of the variation in runoff. Spatial and temporal distribution of rainfall and runoff affects salinity migration inland and data are, therefore, useful for salinity management in the Casamance River basin.
\end{abstract}

\section{Introduction}

Rainfall and runoff deficits have been observed in the Sahelian countries since 1968, and drought has, consequently, persisted throughout this region of the African continent. This situation has led to design and implementation of many water management projects to protect agriculture from adverse climate change. For instance, the South Zone Water Management Project (SZWMP) is among the many projects which have undertaken construction of many hydraulic structures, such as anti-salt and retention dikes, to control water quantity and quality throughout the Casamance River valley and to reclaim saline soils. The main objective of this project, co-founded by USAID and the Senegalese Government, is to increase rice production by using improved water management techniques in the Ziguinchor and Kolda regions of southern Senegal. The total area to be reclaimed and protected is approximately 15 000 ha of unsalted and salted soils across 60 valleys in the Kolda and Ziguinchor regions. The successful implementation of the project requires a knowledge of the space, time, and frequency characteristics of rainfall and runoff.

This study is a part of the SZWMP's programme which began in 1991 by Louis Berger International, Inc. and Louisiana State University Agricultural Center in collaboration with Senegalese technicians. It empirically investigates the spatial and temporal distribution of rainfall in the Casamance River basin in Senegal, and determines whether rainfall has declined and temperature has increased as a result of climate change. Decline in rainfall and runoff on one hand and increase in evaporation due to increase in temperature on the other hand constitute two of the determinants for the degree of salinity intrusion in the Casamance River basin.

* To whom all correspondence should be addressed

용 (001)-(225)-578-6697; fax: (001)-(225)-578-8652 or 6588; e-mail: cesing@1su.edu

Received 6 June 2001; accepted in revised form 4 June 2002.

\section{Casamance River basin}

Senegal, the most western country in Africa, is located between $12^{\circ} 30^{\prime} \mathrm{N}$ to $16^{\circ} 30^{\prime} \mathrm{N}$ and $11^{\circ} 30^{\prime} \mathrm{W}$ to $17^{\circ} 30^{\prime} \mathrm{W}$, covers an area of $196722 \mathrm{~km}^{2}$, and has a $600 \mathrm{~km}$ Atlantic coastline. It is bordered by Guinea Bissau and Guinea Conakry on the south, by Mali on the east, and by Mauritania, across the Senegal River, on the north. The Casamance River basin, as shown in Fig. 1, is entirely located in Senegalese territory, and has an area of $20150 \mathrm{~km}^{2}$. Its geographic co-ordinates are $12^{\circ} 30^{\prime}$ to $13^{\circ} 21^{\prime}$ latitude north and $14^{\circ} 17^{\prime}$ to $16^{\circ} 47^{\prime}$ longitude west. These co-ordinates show that the longitudinal extension ( $270 \mathrm{~km}$ from west to east ) is greater than the latitudinal extension ( $100 \mathrm{~km}$ from north to south). The hydrological behaviour of the basin is influenced by the combination of climate, topography, hydrography and wave propagation from the sea (saline water intrusion). In the eastern part of Senegal, most of the territory is up to $100 \mathrm{~m}$ above mean sea level (amsl). Thus, Senegal is located between semi-arid and humid inter-tropical regions of the African continent.

\section{Climate}

The climate of the Casamance River basin is characterised by large precipitation variability from north to south ranging between 100 $\mathrm{mm}$ and $1800 \mathrm{~mm}$ during summer, and high temperatures throughout the year (Thiam and Singh, 1997). There are three major atmospheric influences: the Acores anticyclones that bring maritime winds, named Alize, on the coast; the Saharan high depression responsible for the hot and dry winds of the dry season, named Harmattan; and the Saint-Helen anticyclones that are responsible for rainfall. The Inter-Tropical Convergence Zone (ITCZ) follows the movement of the sun and separates these two latter air masses.

From January to March the ITCZ is located south of Senegal, and from April it moves north, covers all the country around July to August, and moves southward with the sun. The length of the rainy season varies from five and half months in the south-east to 


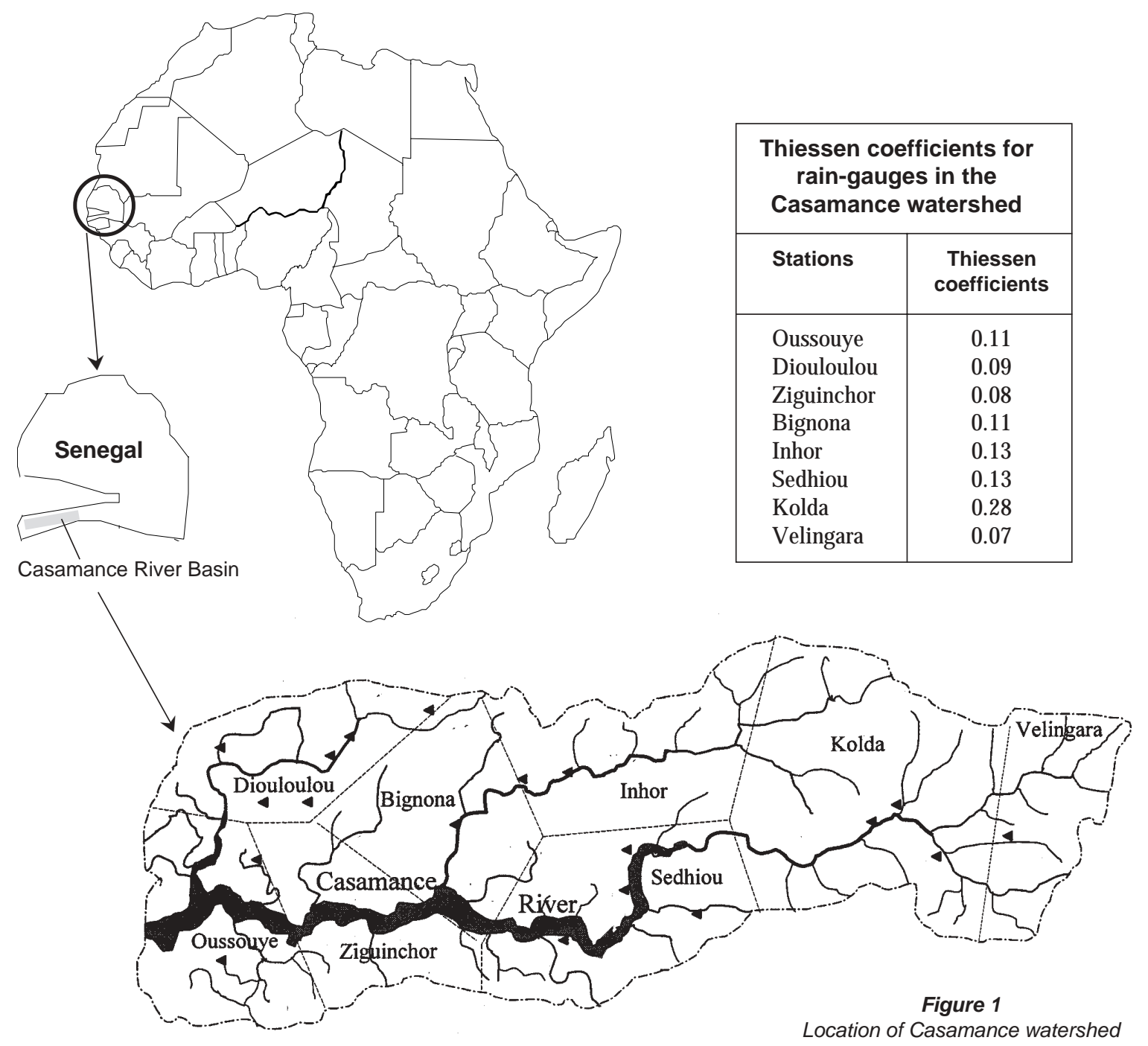

two and half months in the north and northwest. The average temperature increases from the coast to the interior. The highest temperatures are recorded in April, May, and June; on average the temperatures are between $24^{\circ}$ and $29^{\circ} \mathrm{C}$. The evaporation rate is very high, $2000 \mathrm{~mm}$ to more than $4200 \mathrm{~mm} / \mathrm{a}$ in the north and the centre of the country. Any fluctuation in rainfall can have a significant impact on agricultural production. It is, therefore, no surprise that rainfall is the most studied climatological parameter in Sahel. Many studies have focused on drought since the mid1960s and others have analyzed the general trend. The climate of the Casamance region is "Soudano-Guinean" or tropical and favourable for agriculture and many other pursuits. The country has two marked seasons: wet (or rainy) and dry. A great variability of annual rainfall has been observed during the last two decades. For the period 1958 to 1970 the average annual rainfall was $1600 \mathrm{~mm}$ in the south and $400 \mathrm{~mm}$ in the north. It has decreased for the period 1971 to 1992 to $1200 \mathrm{~mm}$ in the south and $200 \mathrm{~mm}$ in the north. This diminution has reached $200 \mathrm{~mm}$ to $400 \mathrm{~mm}$ at some locations (MH/ PNUD/DADSG-SEN, 1994). The highest average daily temperature usually occurs between April and June, where it may reach $35^{\circ} \mathrm{C}$ $\left(95^{\circ} \mathrm{F}\right)$. The lowest average daily temperature is about $14^{\circ} \mathrm{C}\left(57^{\circ} \mathrm{F}\right)$ and occurs in January (MH/SEN, 1972 to 1992).

\section{Mechanisms of precipitation}

The occurrence of precipitation is related to the mechanisms of its generation. These mechanisms are dictated by the general atmospheric circulation, which determines the type of weather and precipitation within the Casamance River basin. The location of West Africa between two large relatively homogeneous surfaces, land and water, encourages two air masses to develop. These are the tropical continental (cT) air mass and the tropical maritime (mT) air mass; the seasonal migration and pulsation thereof are the fundamental bases of West African climates. Senegal, throughout its territory, is influenced by the same climatic patterns. By its position, the warm, dry, and dusty tropical continental air originates over the Sahara Desert located at the southern border of the country, while the warm and humid tropical maritime air originates over the Atlantic Ocean, which constitutes the western border of the country. The separation of the two air masses is a zone, referred to as the inter-tropical discontinuity zone, also called the inter-tropical convergence zone or the inter-tropical front (ITF). Consequently, throughout the Casamance River basin, two main types of climates are observed: The maritime trade wind, originating over the Açores anticyclone located in the south Atlantic Ocean, is oriented toward the north to north-west. This air mass, in spite of its humidity, is not able to generate much precipitation. The Saharan continental trade 


\begin{tabular}{|c|c|c|c|c|}
\hline \multicolumn{5}{|c|}{$\begin{array}{c}\text { TABLE } 1 \\
\text { Rainfall-runoff measuring stations }\end{array}$} \\
\hline \multirow[t]{2}{*}{ Time interval } & \multicolumn{2}{|c|}{ Rain-gauging station } & \multicolumn{2}{|c|}{ Rainfall measuring station } \\
\hline & $\begin{array}{l}\text { Period of } \\
\text { record }\end{array}$ & Stations (A) & $\begin{array}{l}\text { Period of } \\
\text { record }\end{array}$ & Stations (B) \\
\hline $\begin{array}{l}\text { Monthly for } \\
\text { stations (A); } \\
\text { Yearly for } \\
\text { stations (B) }\end{array}$ & $1951-1990$ & $\begin{array}{l}\text { Diouloulou, Oussouye, } \\
\text { Bignona, Ziguinchor, Inhor, } \\
\text { Sedhiou, Koldaand Velingara }\end{array}$ & $1924-1990$ & $\begin{array}{l}\text { Ziguinchor, Inhor, Bignona, Sedhiou, } \\
\text { Diouloulou, Kabrousse, Tanghory, Oussouye, } \\
\text { Tendouck, Marssassoum, Djibidione, Loudia- } \\
\text { Wolof, Niaguis, Nyassia, Sindian, Toukara, Baila, } \\
\text { Alakounda, Kartiak, Kolda, Basse, Velingara, } \\
\text { Kounkane, Bonconto, Dabo, Diattacounda, } \\
\text { Fafacourou, Medina Yoro Foula, Tanaff, Bafata, } \\
\text { Gabu, Pirada, and Yundum }\end{array}$ \\
\hline Yearly & $1935-1985$ & \multicolumn{3}{|c|}{ Runoff measuring stations: Kolda, Sare Keita, Sara Sara, Medina Omar, Toukara } \\
\hline
\end{tabular}

wind, called Harmattan, is oriented toward the east. It is characterised by drought and marked thermic amplitude - cold during the night and hot during the day - with dry mist.

\section{Rainfall characteristics}

Three types of rainfall are mainly observed in Senegal:

- precipitation (events) related to the "grains-lines" at the beginning and the end of the rainy season; these are perturbations over short periods with high-intensity rainfall;

- monsoon rainfall, when the season is well installed, with longduration precipitation of low intensity; and

- some rare rainfall events called " pluies de mangues", which can be described as scattered light rainfall, and occur occasionally between December and March.

The rainy season lasts from mid-May to mid-September, and the dry season lasts for the remainder of the year. The first rainfall events occur around May 15 in Casamance, in the south-west of the country, and progress north toward the end of June.

Two cycles are observed in rainfall patterns in Senegal and Gambia. The rainfall data show a long span where wet decades alternate with dry decades, and a short span which is highly variable and is estimated to last about 5 years. Also, it is generally accepted by policy makers that the variability of rainfall has been on the rise and its annual amount on the decrease since the mid-1960s. The significance of this phenomenon is interpreted in two ways. Firstly, the decrease between 1967 and 1984 is a minor fluctuation that often occurred in the past. Accordingly, a trend of drying climate cannot be concluded. Even if there were a change in the climate, the change is not consistent as an examination of 10 years of data shows.

Secondly, an analysis of annual rainfall at 33 stations and monthly rainfall at 8 stations, well distributed throughout the Casamance watershed, for the period 1924 to 1990 showed a predictable pattern of fluctuation of the 5-year mean around the long-term mean. The 5-year moving mean eliminated sharp fluctuations in the annual values and exhibited an alternating pattern of increasing and decreasing rainfall, with a general decreasing trend starting around the mid 1960s. Adequate documentation related to runoff within the entire Casamance River basin, however, is not available.

\section{Hydrography}

The project area lies on the southern coast of Senegal and is an area of gentle topographic relief. It slopes generally to the east. The highest point of the basin is located between Fafacourou and Velingara and its altitude is $50 \mathrm{~m}$ amsl. As a consequence of low relief, the land surface is characterised by flood plains and meandering belt-type topography. The drainage system of the project area consists of the Casamance River which rises in the south-eastern highlands and flows towards the Atlantic Ocean.

The Casamance River is formed by the confluence of many small streams which are often dry during the dry season (October to April), and runoff is perennial in the downstream part from Fafacourou. The stream-beds are in the middle of small valleys. The gauging station of Kolda mainly controls runoff from the upper part of the Casamance basin (drainage area at Kolda gauging station $=3700 \mathrm{~km}^{2}$ ). Diana Malary, around $30 \mathrm{~km}$ downstream of Kolda, is the boundary of the seawater intrusion. Between Diana Malary and Sefa the bed gradually rises up to a distance of about 2 $\mathrm{km}$ at Sefa.

The confluence of the Casamance River and its main tributary, the Sougrougrou River, is located at the environs of Adeane. Like the Casamance River, the Sougrougrou River is formed by many small tributaries which begin in the vast forest region of Pata and Guimara. The width of the Sougrougrou River is less than that of the Casamance River $(1 \mathrm{~km})$. The characteristics of the Casamance River remain unchanged after its confluence with the Sougrougrou. Its width shrinks between Niaguis and its confluence with Lake Bignona, and extends $8 \mathrm{~km}$ upstream from Karabane.

Downstream from Ziguinchor, the tributaries of the Casamance River, called "Bolons", are Bignona, Diouloulou (right bank) and Kamobeul Bolon (left bank). A great delta characterises the Casamance River mouth (coastal area). The intrusion of sea-water begins from the coast towards the continental part of the basin. As a result, the hydrometric network can be divided into two main parts: the basin network under tidal influence and the continental basin network. In the saline/estuarine part of the Casamance River, runoff is influenced by tidal wave propagation. The tidal wave intrudes into the bed of the Casamance River and its tributaries up to a distance of $200 \mathrm{~km}$.

Freshwater enters the Casamance River estuary by canal discharge, storm drains, direct land runoff, and subsurface flow. 


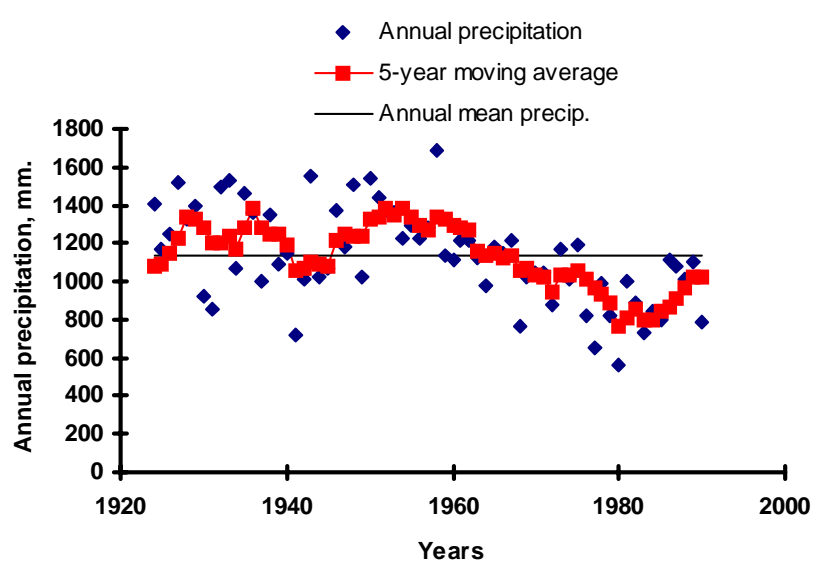

Figure 2

Annual rainfall times series, for 1924 to 1990, at Kolda, Casamanve River basin

Freshwater inflow is seasonal, and most of it is caused by heavy rainfall and occurs during the wet season (May to November).

\section{Hydrological data}

Observations of rainfall, runoff, climatic parameters, such as temperature, humidity, wind speed, and radiation and salinity $(\mathrm{g} / \mathrm{l})$ within the basin have been made. The Senegalese National Meteorological Office is responsible for monitoring via the hydrometeorological network. The hydrological network is monitored by the Senegalese National Subdivision of Water Resources. Organised collection of data is, however, lacking due to the fact that these two central institutions are not attached to the same department. In addition, different water resource projects under their direction are not co-ordinated. Consequently, the data for this study were drawn from different sources which are not always easily accessible. In the past, many measurement stations called "project stations" proliferated throughout the country without standardisation of sampling methods. Such a situation makes the task of gathering data very difficult, even though the data may exist but are in non-standard form. The analysis of precipitation and runoff data in this study is based on monthly and annual records of some representative stations well distributed throughout the basin. The monthly rainfall study is limited to the period 1951 to1990 for 8 stations which are distributed throughout the basin, while the annual rainfall record includes 33 stations for the period 1924 to 1990, as shown in Table 1. Monthly rainfall data were not available for any stations other than the above 8 stations. The runoff study is limited to the period 1935 to 1986 for 5 streamflow gauging stations, including Kolda, Sare Keita, Sare Sara, Medina Omar, and Toukara. They are all located in the continental portion of the basin. Only the annual runoff record is available for these stations. This situation makes the water resource assessment difficult for the Casamance River basin.

\section{Analysis of annual data}

Annual rainfall, runoff and temperature affect salinity in the Casamance River basin. Therefore, a spatial and statistical analysis undertaken within the Casamance River basin, included detection of trends in the rainfall and temperature data, estimation of changes in the rainfall and runoff quantiles, and assessment of rainfall and runoff variability in space and time. For each rainfall series, the 5year moving average was chosen to remove periodicity and identify trends in the data. Using the power transformation method (Chander

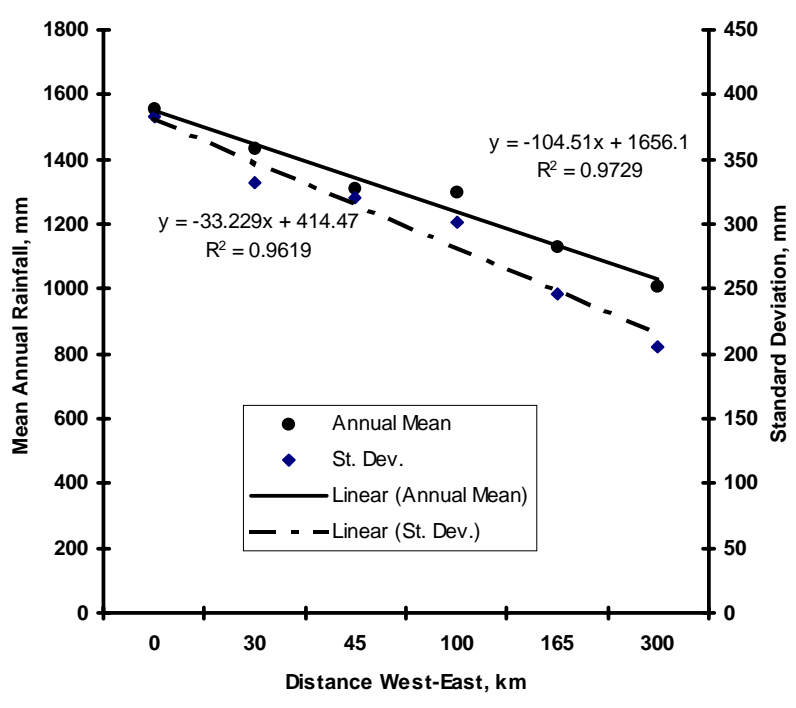

Figure 3

Mean annual rainfall and standard deviation distribution from west to east

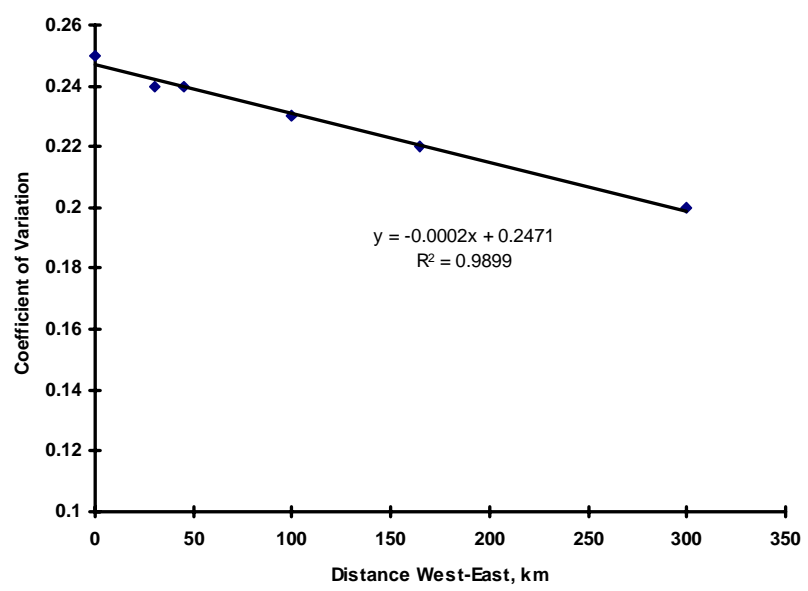

Figure 4

Coefficient of variation distribution from west to east

et al., 1978; and Jain and Singh, 1986), the rainfall and runoff quantiles were estimated using the Normal distribution. The surfacewater resources in the Kolda region were evaluated using the procedure developed by Hargreaves (1995).

\section{Estimation of mean areal rainfall}

Many factors affect the spatial distribution of rain falling on the ground and a method of estimating the mean areal rainfall must be able to represent the rainfall distribution in a reasonable manner (Singh,1992). The Thiessen polygon method was used to estimate the Casamance watershed mean rainfall for 1951 to 1990 :

$$
P=\sum a_{i} P_{i} \sum a_{i}=1 \text { and } 0<1, i=1,2, \ldots . n
$$

where:

$P$ is the mean areal (watershed) rainfall

$\mathrm{P}_{\mathrm{i}}$ is the rainfall of the $i$-th raingauge, $i=1,2,3, \ldots \ldots n$

$n$ is the number of raingauges

$a_{i}=A_{i} / A$ is the $i$-th weight of the -th rainfall station

$A_{i}$ is the Thiessen polygon area of the $i^{\text {th }}$ rain-gauge

$A$ is the total drainage area. 




The Thiessen coefficients for different stations in the Casamance River basin are shown in Fig. 1. This method is reliable for the Casamance River basin due to its flatness.

\section{Temporal analysis}

For illustrative purposes, a sample of 8 representative stations was chosen, based on the quality of records, from among the 33 stations. 

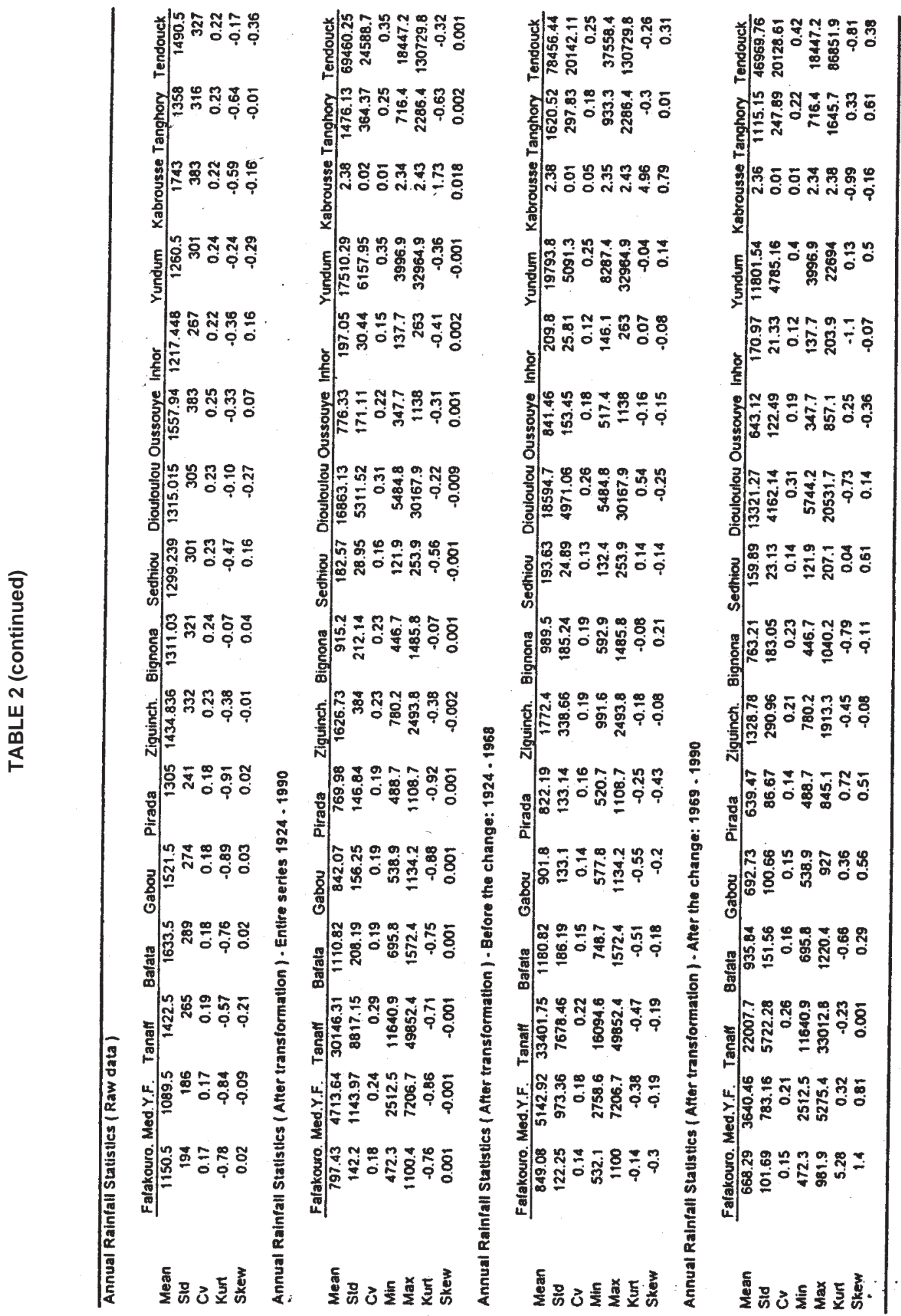

The chosen stations have good quality records. Figure 2 shows a plot of annual rainfall time series with a 5-year moving average for a sample station. Based on the graphs, the suspected change in rainfall trend is around 1960 to 1970 . Based on the annual rainfall time series of different stations, the year 1968 was found to be the breakdown year. The inter-annual mean rainfall coefficient of variation and standard deviation, for 1924 to 1990 , throughout the basin ranged from $137 \mathrm{~mm}$ to $338 \mathrm{~mm}$ and 0.16 to 0.23 , respectively; and the annual mean rainfall over the basin was $548 \mathrm{~mm}$. A

homogeneity test showed that the pre-change and post-change annual rainfall series were all homogeneous at the 5\% significance level because the variance ratios were less than 1.04.

\section{Spatial analysis}

The annual rainfall decreased from the coast to the interior as shown in Fig. 3. The decrease is also shown by the standard deviation and the coefficient of variation as shown in Fig. 4. Effects 


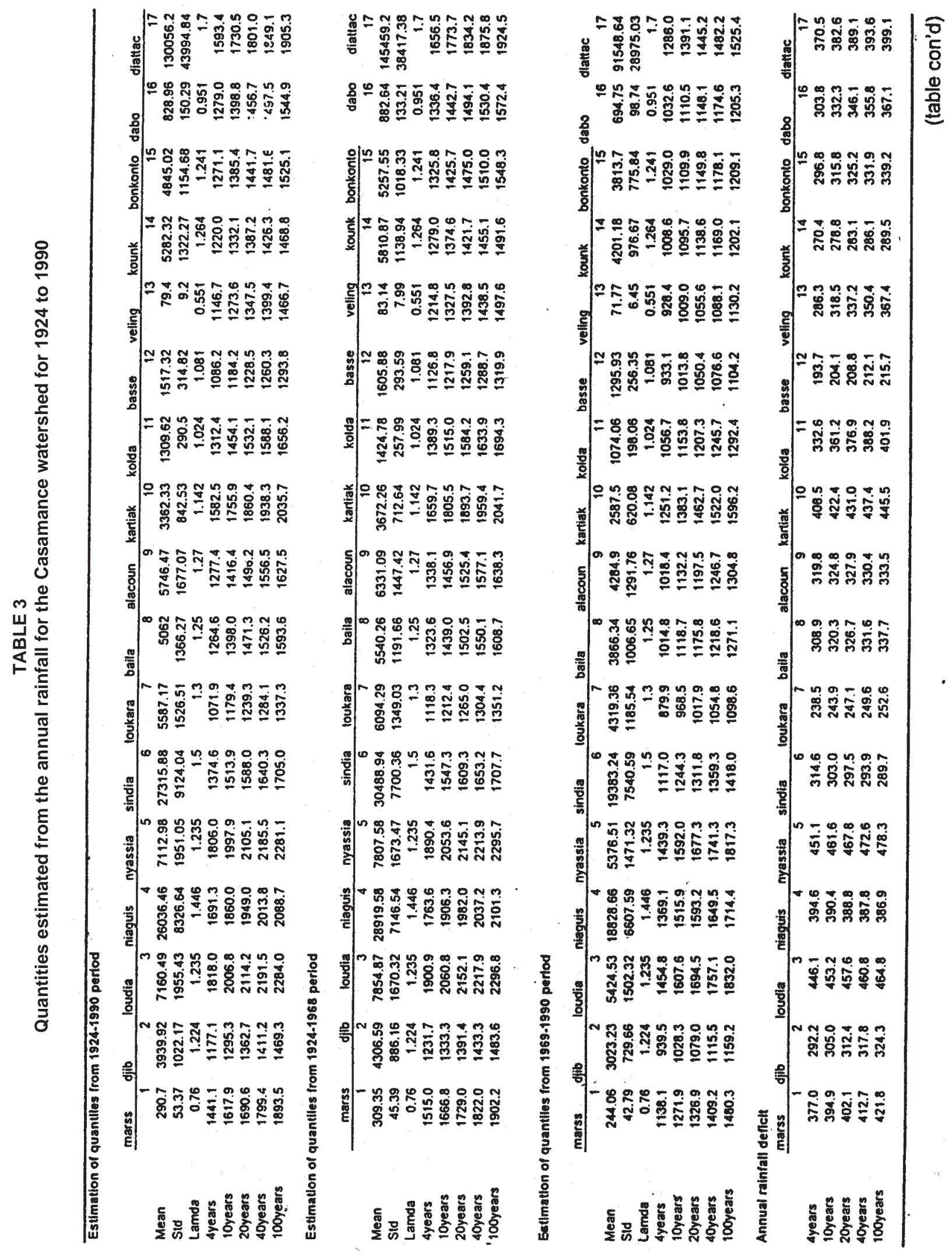

of continentality and orientation of topography among other factors discussed by Singh (1992) explain the decreasing trend of these curves expressing the mean, standard deviation, and coefficient of variation with respect to distance from the coast. The maritime air carrying moisture over land penetrates the basin from west to east.
The moisture-carrying capacity is affected by the topography which slopes gently upward toward the east. As a result, rainfall decreases gradually from the coast to the interior. Therefore, the higher the altitude, the less the precipitation in the Casamance River basin. 


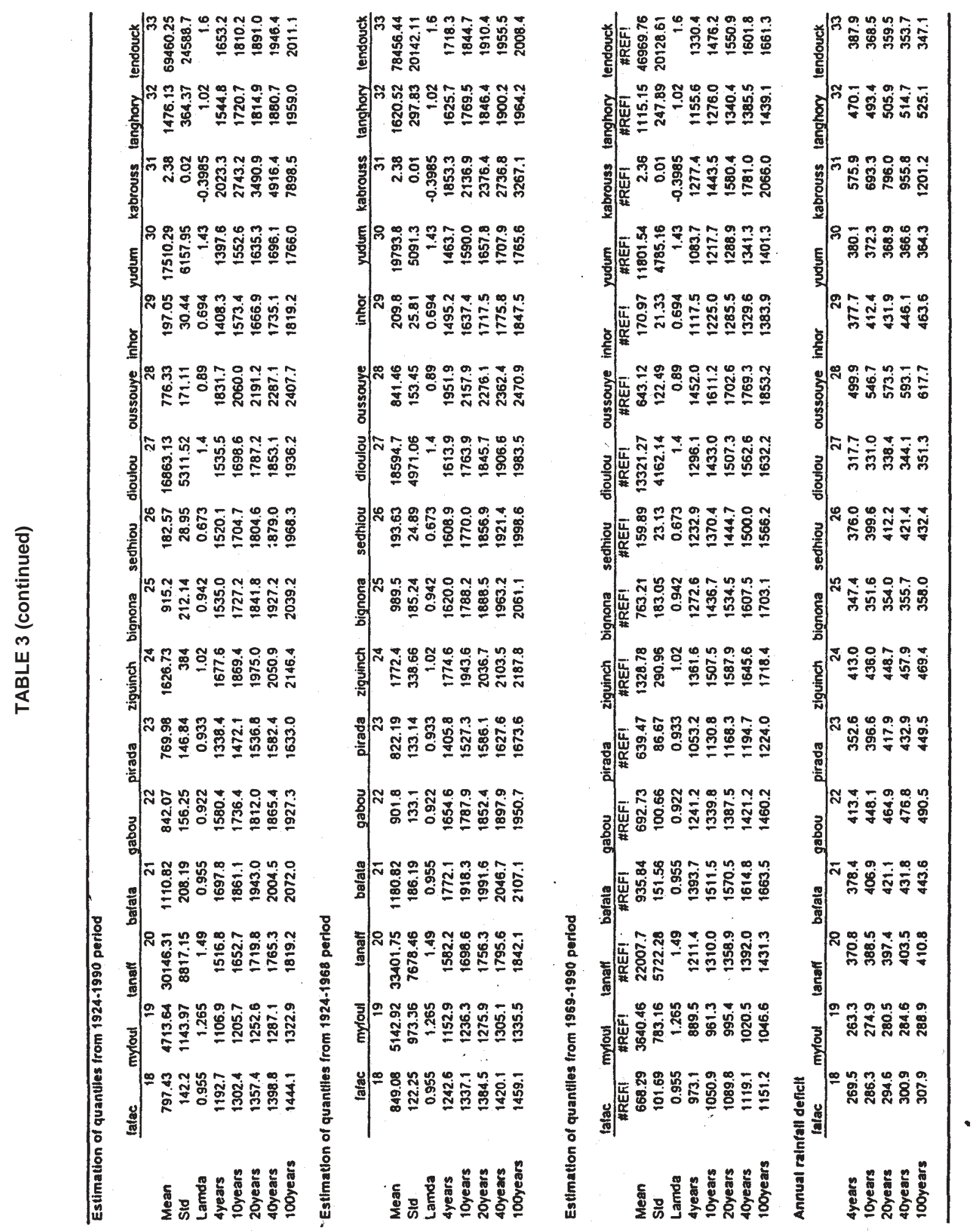

\section{Frequency analysis}

Using the power transformation method described by Jain and Singh (1986), annual rainfall data were transformed so that their frequency distribution would be normal. The transformed data were then used for frequency analysis of annual rainfall of each station. The statistical parameters for both the annual rainfall raw data and the transformed annual rainfall data are shown in Table 2. By comparing the data before and after the supposed climate change starting at around 1968, it is seen that the mean average rainfall has consistently declined in the post-change period, whereas the coefficient of variation has increased. This observation is important for planning and operation of irrigation facilities in the Casamance River basin. To evaluate if the decline in the annual rainfall data also occurs in the frequency domain, the Normal distribution quantiles were computed for 4-year, 10-year, 20-year, 40-year and 100-year recurrence intervals, as shown in Table 3. Also shown in the table are quantiles of rainfall deficits which were 


\section{TABLE 4 \\ Statistical parameters on annual temperature}

\begin{tabular}{|l|c|c|c|}
\hline \multicolumn{3}{|c|}{ Period 1951 to 1990} \\
& & Station & \\
\cline { 2 - 4 } & Ziguinchor & Kolda & Velingara \\
\hline Mean & 26.9 & 27.6 & 28.6 \\
Mini & 26.1 & 26.7 & 27.2 \\
Max & 27.8 & 28.4 & 30 \\
Std & 0.4 & 0.3 & 0.7 \\
Cv & 0.017 & 0.014 & 0.025 \\
\hline
\end{tabular}

Period 1951 to 1968

\begin{tabular}{|l|c|c|c|}
\hline & & Station & \\
\cline { 2 - 4 } & Ziguinchor & Kolda & Velingara \\
\hline Mean & 26.5 & 27.6 & 28 \\
Mini & 26.1 & 26.8 & 27.2 \\
Max & 27 & 28.3 & 28.6 \\
Std & 0.2 & 0.3 & 0.3 \\
Cv & 0.009 & 0.014 & 0.013 \\
\hline
\end{tabular}

Period 1969 to 1990

\begin{tabular}{|l|c|c|c|}
\hline \multirow{2}{*}{} & \multicolumn{3}{|c|}{ Station } \\
\cline { 2 - 4 } & Ziguinchor & Kolda & Velingara \\
\hline Mean & 27.2 & 27.6 & 29 \\
Mini & 26.5 & 26.7 & 27.8 \\
Max & 27.8 & 28.4 & 30 \\
Std & 0.3 & 0.4 & 0.6 \\
Cv & 0.014 & 0.015 & 0.021 \\
\hline
\end{tabular}

defined as the difference between the amount of rainfall before 1968 and that after 1968 for the same annual probability of occurrence or recurrence interval. It is found that the values of the quantiles have decreased in the post-change period, reinforcing the conclusion reached based on the mean values. Indeed the change is quite perceptible and has an important bearing on the structures built for irrigation and salinity management in the Casamance River basin. If the change exhibited by decreasing rainfall persisted, many of the structures would be found to have been over-designed.

\section{Analysis of temperature}

Temperature was used as a fundamental climate indicator and temperature change as an indicator of climate change. The temperature data were analysed for three stations: Ziguinchor, Kolda, and Velingara. These stations by their position represent three different areas of the Casamance River basin: the lower, medium and high elevation Casamance. These areas can be characterised by a longitudinal transect almost joining the coast (Ziguinchor) to the upstream limit of the basin (Velingara). The mean annual temperatures, for 1951 to 1990 , at Ziguinchor, Kolda, and Velingara are $26.9^{\circ} \mathrm{C}, 27.6^{\circ} \mathrm{C}$, and $28.6^{\circ} \mathrm{C}$, respectively. As shown in Table 4, these means increased statistically significantly from the pre-change period (1951 to 1968) to the post-change period (1969 to 1990). For the long-term period, the standard deviation ranged from $0.3^{\circ} \mathrm{C}$ to $0.7^{\circ} \mathrm{C}$, and the coefficient of variation from $0.014^{\circ} \mathrm{C}$ to $0.025^{\circ} \mathrm{C}$. The temperature time series
TABLE 5

Statistical parameters of runoff for different periods at different stations $(\mathrm{mm})$

Statistical parameters for 1935 to 1986

\begin{tabular}{l|c|c|c|c|c|} 
& Kolda & Sare Sara & Madina & Sare Keita & Toukara \\
Mean & 4.059 & 1.188 & 0.598 & 0.163 & 0.038 \\
Std & 2.427 & 0.579 & 0.315 & 0.089 & 0.021 \\
Cv & 0.60 & 0.49 & 0.53 & 0.55 & 0.55 \\
Mini & 0.22 & 0.108 & 0.09 & 0.004 & 0.001 \\
Max & 8.9 & 2.42 & 1.26 & 0.342 & 0.093 \\
Skewness & 0.009 & -0.04 & -0.06 & -0.01 & 0.03 \\
\hline
\end{tabular}

Statistical parameters for 1935 to 1968

\begin{tabular}{l|c|c|c|c|c|} 
& Kolda & Sare Sara & Madina & Sare Keita & Toukara \\
Mean & 5.222 & 1.475 & 0.761 & 0.203 & 0.047 \\
Std & 1.837 & 0.44 & 0.23 & 0.072 & 0.018 \\
Cv & 0.35 & 0.30 & 0.30 & 0.35 & 0.38 \\
Mini & 0.761 & 0.516 & 0.184 & 0.009 & 0.001 \\
Max & 8.9 & 2.42 & 1.26 & 0.342 & 0.093 \\
\hline
\end{tabular}

Statistical parameters for 1969 to 1986

\begin{tabular}{|l|c|c|c|c|c|} 
& Kolda & Sare Sara & Madina & Sare Keita & Toukara \\
\hline Mean & 1.863 & 0.648 & 0.289 & 0.088 & 0.022 \\
Std & 1.821 & 0.394 & 0.199 & 0.067 & 0.015 \\
Cv & 0.98 & 0.61 & 0.69 & 0.76 & 0.68 \\
Mini & 0.22 & 0.108 & 0.09 & 0.004 & 0.001 \\
Max & 7.07 & 1.25 & 0.762 & 0.253 & 0.048 \\
& & & & & \\
\hline
\end{tabular}

with a 5-year moving average of annual temperature exhibited an increase in the mean temperature from the coast (low Casamance) to the interior (high Casamance). Therefore, the further the distance from the ocean, the greater the temperature range (Singh, 1992). The temperature analysis indicated that the climate changed from around the mid-1960s throughout the Casamance River basin. The temperature increase would increase evaporation and exacerbate salinity in the basin.

\section{Temporal and spatial analysis of annual runoff}

The annual runoff analysis was performed for five stations located upstream in the Casamance watershed. They were Kolda, Madina Omar, Sare Sara, Sare Keita, and Toukara. The drainage area of the Casamance River at Kolda is $3700 \mathrm{~km}^{2}$. Except for the Toukara Station, all others are inside the Casamance River watershed at Kolda. The coefficient of variation of the annual discharge for 52 years (1935 to 1986) ranged from 0.49 to 0.60 , denoting the spatial variability of runoff over the Casamance River basin. This variability is more pronounced in three different periods shown in Table 5 at different stations. For instance, the coefficient of variation for 1935 to 1986,1935 to 1968 , and 1969 to 1986 at Kolda Station is 0.60 , 0.35 , and 0.98 , respectively. The runoff time series plots with 5year moving average for the whole period (1935 to 1986) as well as the pre-change (1935 to1968) and the post-change periods showed a decreasing runoff pattern from approximately 1968 to 1986 at different stations, while the values related to the pre-change period appeared more stable around the mean than for the postchange period. 
TABLE 6

Quantiles estimated from the annual discharges, for 1935 to 1986 at different stations $(\mathrm{mm})$

Estimation of quantiles for 1935 to1986

\begin{tabular}{|l|c|c|c|c|c|}
\hline & Kolda & Sare Sara & Madina & Sare Keita & Toukara \\
\hline $5 \%$ & 0.382 & 0.14 & 0.107 & 0.028 & 0.001 \\
$10 \%$ & 0.761 & 0.367 & 0.16 & 0.05 & 0.008 \\
$25 \%$ & 2.02 & 0.914 & 0.299 & 0.08 & 0.026 \\
$50 \%$ & 4.055 & 1.2 & 0.622 & 0.157 & 0.039 \\
$75 \%$ & 6.38 & 1.52 & 0.873 & 0.24 & 0.053 \\
$90 \%$ & 6.9 & 1.98 & 0.983 & 0.269 & 0.063 \\
\hline
\end{tabular}

Estimation of quantiles for 1935 to1968

\begin{tabular}{|l|c|c|c|c|c|}
\hline & Kolda & Sare Sara & Madina & Sare Keita & Toukara \\
\hline $5 \%$ & 1.95 & 0.668 & 0.306 & 0.08 & 0.009 \\
$10 \%$ & 3.29 & 1.03 & 0.519 & 0.125 & 0.028 \\
$25 \%$ & 3.92 & 1.17 & 0.603 & 0.148 & 0.036 \\
$50 \%$ & 5.35 & 1.38 & 0.754 & 0.219 & 0.046 \\
$75 \%$ & 6.7 & 1.86 & 0.947 & 0.259 & 0.061 \\
$90 \%$ & 7.02 & 2.01 & 1.02 & 0.288 & 0.075 \\
\hline
\end{tabular}

Estimation of quantiles for 1969 to1986

\begin{tabular}{|l|c|c|c|c|c|}
\multicolumn{6}{|c|}{ Estimation of quantiles for 1969 to1986 } \\
\hline & Kolda & Sare Sara & Madina & Sare Keita & Toukara \\
\hline $5 \%$ & 0.22 & 0.108 & 0.09 & 0.004 & 0.001 \\
$10 \%$ & 0.32 & 0.13 & 0.106 & 0.028 & 0.001 \\
$25 \%$ & 0.52 & 0.34 & 0.151 & 0.05 & 0.008 \\
$50 \%$ & 1.11 & 0.57 & 0.195 & 0.07 & 0.023 \\
$75 \%$ & 2.38 & 0.98 & 0.361 & 0.091 & 0.028 \\
$90 \%$ & 4.89 & 1.24 & 0.65 & 0.231 & 0.047 \\
\hline \multicolumn{7}{|l|}{ Runoff deficit up to 1968 } \\
\hline \multicolumn{7}{|l|}{ Kolda } & Sare Sara & Madina & Sare Keita & Toukara \\
\hline $5 \%$ & 1.73 & 0.56 & 0.216 & 0.076 & 0.008 \\
$10 \%$ & 2.97 & 0.9 & 0.413 & 0.097 & 0.027 \\
$25 \%$ & 3.4 & 0.83 & 0.452 & 0.098 & 0.028 \\
$50 \%$ & 4.24 & 0.81 & 0.559 & 0.149 & 0.023 \\
$75 \%$ & 4.32 & 0.88 & 0.586 & 0.168 & 0.033 \\
$90 \%$ & 2.13 & 0.77 & 0.37 & 0.057 & 0.028 \\
\hline
\end{tabular}

TABLE 7

Linear equations of rainfall-runoff realtion

\begin{tabular}{|l|l|l|l|}
\hline $\begin{array}{l}\text { Rain-gauge } \\
\text { stations } \\
\text { [1] }\end{array}$ & $\begin{array}{l}\text { Stream-gauge } \\
\text { stations } \\
\text { [2] }\end{array}$ & $\begin{array}{l}\text { Equations } \\
(\mathbf{P}=\text { rainfall; } \mathbf{R}=\text { runoff }) \\
{[\text { [3] }}\end{array}$ & $\mathbf{R}^{\mathbf{2}}$ \\
\hline [4]
\end{tabular}

\section{Frequency analysis of annual runoff}

On checking the skewness of annual runoff (in $\mathrm{m}^{3} / \mathrm{s}$ ) data, the Normal distribution was found suitable. The runoff quantiles at different stations were computed for different probabilities from the Normal probability distribution as shown in Table 6. Also shown in the table are quantiles of runoff deficits for different recurrence intervals. The runoff deficit was defined as the difference between the runoff value before 1968 and that after 1968 for the same probability of occurrence or recurrence interval. It is seen that for the same return period, the runoff quantile significantly decreased during the post-change period. This runoff decrease would translate into increased salinity and the resulting decrease in agricultural productivity in the Casamance River basin.

\section{Rainfall-runoff relation}

The Casamance River watershed has far more rain-gauges than stream-gauging stations and has more rainfall data than runoff data. By relying on rainfall data, runoff was calculated using a linear regression model developed by Hargreaves (1995) as

$$
R=a+b S
$$

where:

$\mathrm{R}$ is the annual runoff

$\mathrm{S}$ is the surplus defined as the difference between annual rainfall (R) annual evaporation (E)

$\mathrm{a}$ and $\mathrm{b}$ are parameters.

For example, for Madina Omar $\mathrm{a}=0.0302$ and $\mathrm{b}=0.0015$ and the coefficient of determination $=0.7742$; and $\mathrm{a}=0.0359$ and $\mathrm{b}=$ 0.0081 for Kolda and the coefficient of determination $=0.7372$. The coefficients of determination are not great but are acceptable. The mean annual discharge $\left(\mathrm{m}^{3} / \mathrm{s}\right)$ for a given location was correlated with the annual rainfall series (mm). Regardless of the conditions of geology and vegetation cover, the relationship between annual rainfall and the mean annual discharge was good, as indicated by sufficiently high coefficients of determination, as shown in Table 7.

From the quantiles estimated for the whole, pre-change (1935 to1968), and post-change (1969 to1986) periods summarised in Table 6, the annual rainfall deficit and the corresponding mean annual discharge for different return periods at different stations were obtained. It was found that the rainfall deficit is generally amplified in runoff deficit. Once the relationship between rainfall and runoff is established, runoff prediction may be made based on the rainfall data and other climatic parameters, such as temperature.

\section{Analysis of monthly rainfall \\ Temporal analysis}

The monthly rainfall analysis was based on the mean monthly rainfall depths over the Casamance River basin obtained using the Thiessen polygon method, as shown in Fig. 1. During the rainy season, there is pronounced variability in rainfall from one month to another, as shown in Table 8. The coefficient of variation and standard deviation for 1951 to 1990 ranged from 0.26 to 1.68 , and $108 \mathrm{~mm}$ to $130.3 \mathrm{~mm}$, respectively, confirming the great variability of the mean monthly rainfall over the basin. 


\begin{tabular}{|l|c|c|c|c|c|c|c|}
\hline \multicolumn{1}{|c|}{ TABLE 8} \\
$\begin{array}{l}\text { Statistical parameters of the monthly mean rainfall, for } \\
\text { 1951 to 1990 over the Casamance Watershed (mm) }\end{array}$ \\
\hline & May & June & July & Aug & Sept & Oct. & Nov. \\
\hline Mean & 10.5 & 111.6 & 279.3 & 380.9 & 280.0 & 104.3 & 7.0 \\
Mini & 0.0 & 15.2 & 150.2 & 131.1 & 142.9 & 19.0 & 0.0 \\
Max & 36.6 & 234.8 & 438.1 & 915.1 & 482.9 & 275.9 & 51.7 \\
Std & 10.8 & 51.0 & 72.5 & 130.3 & 89.0 & 64.5 & 11.7 \\
Cv & 1.02 & 0.46 & 0.26 & 0.34 & 0.32 & 0.62 & 1.68 \\
Skewness & 1.071 & 0.606 & 0.181 & 1.467 & 0.482 & 1.192 & 2.199 \\
Kurt & -0.019 & -0.089 & -0.402 & 6.435 & -0.399 & 0.791 & 5.116 \\
\hline
\end{tabular}

TABLE 9

Quantiles estimated from the monthly mean rainfall series, for 1951 to 1990 , throughout the Casamance Watershed

Estimation of quantiles for 1951-1990

\begin{tabular}{|l|c|c|c|c|c|c|c|}
\hline & May & June & July & Aug & Sept & Oct. & Nov. \\
\hline $5 \%$ & 0.4 & 45.8 & 160.8 & 174.2 & 155.2 & 28.5 & 0.0 \\
$10 \%$ & 0.7 & 56.5 & 183.1 & 222.5 & 163.2 & 42.9 & 0.1 \\
$25 \%$ & 3.4 & 72.6 & 229.3 & 312.6 & 214.9 & 62.2 & 0.5 \\
$50 \%$ & 6.8 & 97.5 & 274.5 & 381.8 & 265.1 & 86.1 & 3.4 \\
$75 \%$ & 15.5 & 142.6 & 330.3 & 445.9 & 333.6 & 127.7 & 14.6 \\
$90 \%$ & 28.5 & 187.7 & 356.0 & 487.8 & 407.5 & 214.9 & 27.4 \\
\hline
\end{tabular}

Estimation of quantiles for 1951 to 1968

\begin{tabular}{|l|c|c|c|c|c|c|c|}
\hline & May & June & July & Aug & Sept & Oct & Nov \\
\hline $5 \%$ & 0.7 & 63.4 & 131.6 & 154.5 & 149.9 & 57.4 & 1.0 \\
$10 \%$ & 0.7 & 73.0 & 181.3 & 267.7 & 225.9 & 66.7 & 1.1 \\
$25 \%$ & 3.4 & 93.7 & 273.1 & 379.9 & 262.4 & 85.6 & 3.4 \\
$50 \%$ & 5.9 & 128.4 & 320.5 & 415.7 & 315.8 & 120.3 & 12.0 \\
$75 \%$ & 15.3 & 152.9 & 343.8 & 478.2 & 387.6 & 175.9 & 23.3 \\
$90 \%$ & 25.0 & 204.4 & 399.4 & 492.7 & 454.9 & 259.8 & 27.4 \\
\hline
\end{tabular}

Estimation of quantiles for 1969 to1990

\begin{tabular}{|l|c|c|c|c|c|c|c|}
\hline & May & June & July & Aug & Sept & Oct & Nov \\
\hline $5 \%$ & 0.3 & 41.7 & 160.8 & 188.7 & 154.5 & 24.0 & 0.0 \\
$10 \%$ & 0.6 & 50.4 & 184.9 & 212.7 & 156.0 & 33.8 & 0.0 \\
$25 \%$ & 4.7 & 66.0 & 219.2 & 287.1 & 165.7 & 47.9 & 0.2 \\
$50 \%$ & 7.1 & 80.6 & 254.7 & 366.9 & 237.5 & 64.7 & 0.5 \\
$75 \%$ & 17.3 & 124.0 & 304.9 & 395.4 & 284.3 & 95.6 & 8.7 \\
$90 \%$ & 31.3 & 172.4 & 343.8 & 437.0 & 317.3 & 106.7 & 13.6 \\
\hline \multicolumn{7}{|l}{ Monthly Rainfall Deficit } \\
\hline \multicolumn{7}{|l}{} \\
\hline $5 \%$ & 0.4 & 21.8 & -29.1 & -34.2 & -4.6 & 33.4 & 1.0 \\
$10 \%$ & 0.1 & 22.6 & -3.7 & 55.0 & 69.9 & 32.9 & 1.0 \\
$25 \%$ & -1.4 & 27.7 & 53.9 & 92.8 & 96.8 & 37.7 & 3.2 \\
$50 \%$ & -1.2 & 47.7 & 65.9 & 48.8 & 78.3 & 55.6 & 11.5 \\
$75 \%$ & -2.0 & 29.0 & 38.9 & 82.7 & 103.3 & 80.3 & 14.7 \\
$90 \%$ & -6.3 & 32.0 & 55.6 & 55.7 & 137.5 & 153.1 & 13.8 \\
\hline
\end{tabular}

This shows that outside of the 5-month rainy period, there is little rainfall during the rest of the year.

\section{Spatial analysis}

When monthly rainfall was mapped over the basin, it was found to vary from one location to another. Along a west-east transect joining Oussouye, Ziguinchor, Sedhiou, and Kolda Stations, where the respective distances between these stations are approximately 30 , 70 , and $65 \mathrm{~km}$, the monthly rainfall for these stations over a period of 40 years (1951 to 1990) is depicted in Fig. 5. Except for the month of June, the mean monthly value decreases from west to east, or from the coast to the interior. The monthly standard rainfall deviation and coefficient of variation distribution from west to east are shown in Fig. 6. Except for the month of September, it increases with the distance from west to east. For all other months, it remains either constant or increases moderately. The coefficient of variation also shows a similar pattern of variability. This variability is relevant, especially during rainy months.

\section{Frequency analysis}

The monthly rainfall series of each rain-gauge station was partitioned into two sets. The first set consisted of data up to the period 1968, and the second set had the data for the period 1969 onwards. These monthly rainfall data, when plotted as histograms, indicated that they were not normally distributed. Using the power transformation method (Jain and Singh, 1986), the whole mean monthly series and the series related to the prechange and post-change periods were normalised. Since the Normal distribution has zero coefficient of skewness and kurtosis equal to 3 , the efficiency of transformation was judged by checking whether the coefficient of skewness tended to zero for the transformed series. In cases where kurtosis was not always zero in the transformed series, the power transformation method was improved by better accounting for its departure from a value of 3.0 in the coefficient of kurtosis of the transformed data (Jain and Singh, 1986), following the procedure introduced by Box and Tiao (1973) and Tiao and Lund (1970). Table 9 shows quantiles estimated for different periods for the whole series, and for the prechange period and post-change period series. For different return periods, a monthly rainfall deficit was found up to 1968 . These deficits vary from one month to another throughout the chosen return periods. For each recurrence interval, the rainfall quantile is lower for the post-change period than it is for the pre-change period. This would imply lower rainfall for a given frequency and hence lower runoff, leading to increased salinity in the basin.

\section{Conclusions}

The following conclusions are drawn from this study:

- Annual rainfall, monthly rainfall, and temperature data at respectively 33,8 and 3 stations show a decreasing trend in rainfall magnitude, and an increasing trend in mean annual temperature at these stations. 


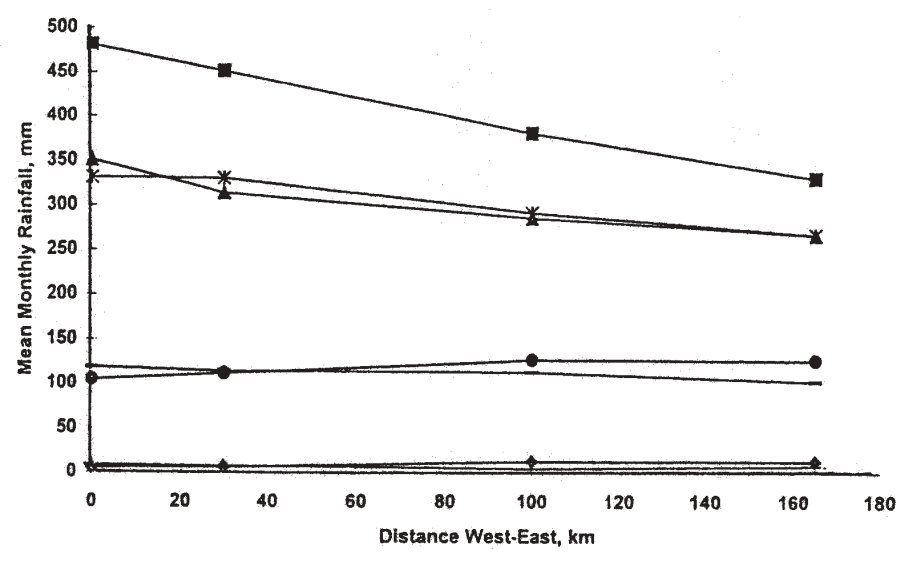

Figure 5

Mean monthly rainfall variability from west to east
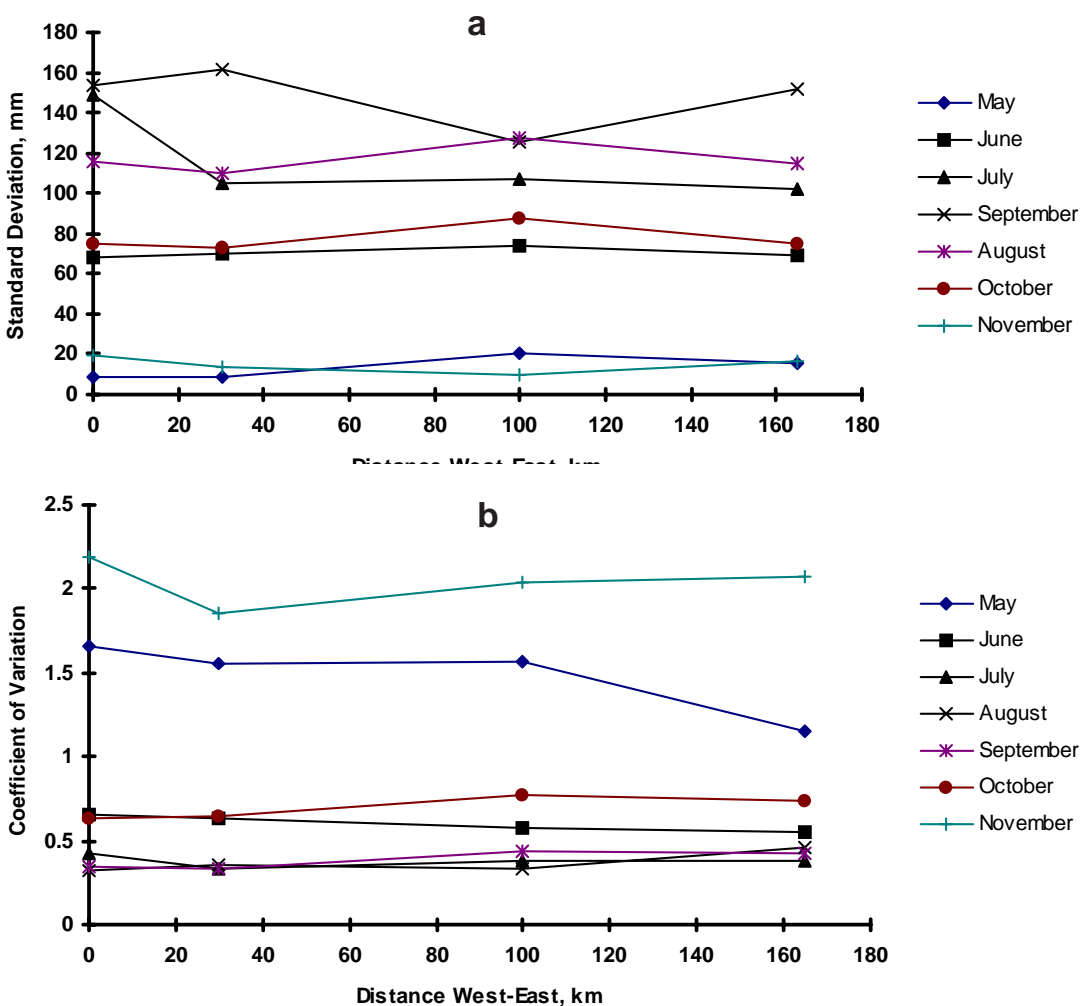

Figure 6

Monthly rainfall standard deviation and coefficient of variation distribution from west to east
- In general, higher temperatures are related to lower precipitation. This is also true for annual values used in this study.

- There is about $0.5^{\circ} \mathrm{C}$ warming in the average annual temperature during the first part (pre1968 period) and $0.7^{\circ} \mathrm{C}$ in the second part (1968 to 1990). The warming trend is also apparent at individual sites.

- Rainfall has decreased since 1968 over the Casamance River basin and temperature has increased simultaneously. The implication is runoff deficit and saline intrusion.

- From the station position and the corresponding rainfall magnitude on monthly and annual bases, a south-north gradual rainfall increase is detected. However, the longitudinal gradient, say, west-east, is not well marked. Consequently, many variabilities are detected in the spatio-temporal rainfall regimes over the Casamance River basin.

\section{References}

BOX GCE and TIAO GC (1973) Bayesian Inference in Statistical Analysis. Addison Wesley Publishing Co., New York, New York.

CHANDER S, SPOLIA SK and KUMAR A (1978) Flood frequency analysis by power transformation. J. Hydraul. Div. ASCE 104 (11) 14951514.

HARGREAVES GH (1995) Estimating SurfaceWater Runoff from Precipitation and Temperature. Unpublished Paper, Utah State University, Logan, Utah.

JAIN D and SINGH VP (1986) A comparison of transformation methods for flood frequency analysis. Water Resourc. Bull. 22(6) 903-911.

MH/PNUD/DADSG-SEN/87/006 (1994) Planification des Resources en Eau. Ministere Hydaulique/Senegal.

MH/SEN (1972-1992) Annaire Hydrologique du Senegal et Publications. Ministere Hydrauliwue/ Senegal.

SINGH VP (1992) Elementary Hydrology. Prentice Hall, Englewood Cliffs, New Jersey.

THIAM EI and SINGH VP (1997) Precipitation, Runoff and Salinity Analysis in the Casamance Watershed Managed by SZWMP. Technical Report WRR, Dept. of Civil and Environ. Eng., Louisiana State Univ., Baton Rouge, Louisiana.

TIAO GC and LUND DR (1970) The use of OLUMV estimates in inference: Robustness studies of the location parameter of a class of symmetric distribution. J. Am. Stat. Assoc. 65. 